\title{
Flattening the Hierarchy Curve: Adaptive Leadership During the Covid-19 Pandemic - A Case Study in an Academic Teacher Training College
}

\author{
Yonit Nissim ${ }^{1} \&$ Eitan Simon ${ }^{1}$ \\ ${ }^{1}$ The Department of Education and teaching Tel- Hai College, Israel \\ Correspondence: Yonit Nissim, the Department of Education and teaching Tel- Hai College,
}

Israel. E-mail: Yonitn@telhai.ac.il

$\begin{array}{lc}\text { Received: January 21, } 2021 & \text { Accepted: February 24, } 2021 \quad \text { Online Published: February 25, } 2021 \\ \text { doi:10.5539/res.v13n1p103 } & \text { URL: https://doi.org/10.5539/res.v13n1p103 }\end{array}$

\begin{abstract}
The Covid-19 pandemic forced institutions of higher education to adopt agile leadership behaviors. The current research aims to examine how the leadership at the Ohalo teacher training college in Israel dealt with the crisis caused by the pandemic. The research hypothesis, predicting a positive relationship between the college leadership's decisions and lecturers' positive evaluations regarding these decisions, was confirmed.

Previous research has given scant attention to the relationship between running an academic institution and applying principles of adaptive leadership during a crisis. This article presents a case study of adaptive leadership at an academic institution during the Covid-19 pandemic. The conclusions suggest that ensuring the continued functioning of an organization during a crisis requires skills and competencies reflecting multifaceted and adaptive leadership, agility, and direct channels of reciprocal, cooperative communication. Opportunities for initiative taking should be provided, and a consistent policy must be maintained that aims to "flatten the hierarchy curve."
\end{abstract}

Keywords: Coronavirus (Covid-19), adaptive leadership, crisis, agility, teacher training

\section{Introduction}

The Covid-19 pandemic forced numerous organizations to undergo significant transformations and changes. Leaders had to rethink key elements of their daily work processes and act in an agile manner. Use of technology was increased in order to maintain operations while adhering to a changing landscape of new health guidelines and procedural regulations.

Institutions of higher education routinely operate in a complex environment that includes regulatory involvement, teaching, and learning. There are frequent and multiple changes in academic, technological, and bureaucratic realms. Even during routine times, there has been an increase in the frequency of changes and the degree of pressure experienced in academic institutions (Amirault \& Visser, 2009).

Moreover, according to Taş̧̧ and Titrek (2020), institutions of higher education in particular need sustainable leadership to maintain their goals. The key to sustainability in institutions of higher education thus seems to be in line with previous research on leadership skills and perspectives. Therefore, we believe that leading such an institution requires an agile and supportive leadership strategy.

In the past several months, since the outbreak of the Covid-19 pandemic, there has been a marked increase in research dealing with leadership in times of crisis. However, prior to that, research in this area has been scarce. In specific, there has been little prior research addressing the relationship between leadership at an academic institution and the application of principles of adaptive leadership during a crisis. The current article seeks to make a modest contribution to this research gap by presenting a case study that demonstrates, in practical terms, what has been described in the theoretical literature on adaptive leadership. In particular, it examines adaptive leadership at a teacher training college as it addressed the consequences of the Covid-19 pandemic.

The last global pandemic, the Spanish flu epidemic, occurred over a century ago, in 1918. At that time, research on leadership was in its infancy. While that epidemic is remembered in the pages of history, it left no insight as to the connection between crises and demonstrations of academic leadership. The current global pandemic of Covid-19 poses multiple complex challenges to institutions of higher education, which were forced to function under conditions of uncertainty. Alongside the health concerns, it became necessary to ensure the continued proper functioning of institutions. One of the many institutions affected is Ohalo College, the subject of the present case study. Ohalo College is an academic institution for the training of educators, located in the northern part of Israel. 
In mid-March 2020, a general closure was imposed in Israel. The institution's leadership decided to continue all activities, while making the necessary adjustments in light of the state of emergency and governmental restrictions. All activity was moved from classroom learning on campus to Emergency Remote Teaching (ERT). This dramatic and agile transition affected the leadership team of 6 senior college officials, 700 courses, 130 lecturers, 40 members of the administrative staff, and 1500 students.

This is an action research study that uses a mixed-methods approach. The qualitative portion is based on document analysis of protocols and analysis of processes recorded in real time. This section describes the decisions and processes undertaken by the college leadership. The quantitative section examines the college lecturers' evaluations regarding these leadership decisions and the transition to Emergency Remote Teaching (ERT).

The current study analyzes these events and the resultant processes undertaken at the college. To the best of our knowledge, there have been few, if any, previous studies examining adaptive leadership processes in an academic organization during a global pandemic. We believe that this unique situation provides fertile ground for reflective research and learning in this field.

\section{Research Questions}

1. What traits were expressed by the Ohalo College leadership during the Covid-19 pandemic?

2. How did the lecturers evaluate the steps taken by the college administration?

3. What key insights can be deduced from this test case to design a model for beneficial leadership of an academic organization during a crisis?

\section{Theoretical Background}

A review of the literature relevant to this subject yields a theoretical framework resting on four key concepts: agility, leadership, adaptation, and crisis, as defined below.

\section{Agility}

It is first important to address our definition of the term "agility." Agility is one of the most important factors in the survival and development of organizations in the current dynamic business environment, characterized by change and uncertainty. We see agility as a key concept in the analysis of the various situations that emerged from the Covid-19 pandemic and the leadership's responses to the crisis. Agility is a relatively new concept, originating in the high-tech industry, specifically in the field of software engineering. It was later applied to organizational theory and human resource management using a situational approach (Overby et al., 2006). Agility refers to the availability, flexibility, and speed of response. Agility in education refers to an approach that implements change, embraces innovation, and transcends traditional conservative patterns of conduct and thinking (Morien, 2018). These definitions were established before the outbreak of the Covid-19 pandemic. It has been previously noted that agility is vital for corporate survival in the contemporary dynamic social environment, which is characterized by change, uncertainty, rapid technological development, increased risk, globalization, and the anticipation of privatization. Agility in an organization synchronizes processes, people, and advanced technology and is considered to be a systematic and strategic organizational value among leaders. Agility has been defined as an ability that requires active use (Goodarzi et al., 2018).

A recent study notes that technological developments of the $21^{\text {st }}$ century have affected institutions of higher education. Therefore, it is important to focus on sustainable leadership in the higher education sector, and highlight applied strategies for lifelong learning, sustainability practices, the difficulties faced, and the experiences shared (Taşçı \& Titrek, 2020). Agility creates a competitive advantage, enabling success in the organizational environment of the Covid-19 pandemic. It is important to note that the college examined in the current study is a teacher training college operating under the auspices of the Israeli Ministry of Education and thus, generally speaking, belongs to the public sector. This sector is not usually among the first to adopt changes or undergo ground-breaking processes.

\section{Leadership}

Leadership is the most influential element on work engagement, because leaders' positive behaviors can establish a healthy work environment in which employees feel motivated and satisfied (Tak et al., 2019). Since the beginning of the twentieth century, the phenomenon of leadership has been one of the most researched topics, yet it remains enigmatic. Over the course of history, more than 350 definitions of "leadership" have been proposed, in the effort to capture this elusive phenomenon in words. However, there is still no unequivocal answer to the question of what distinguishes a person who is a leader from one who is not. Many approaches have attempted to attribute special characteristics or behaviors to leadership, but these have not proven consistent or predictable (Bass, 1960; Cuban, 1988; Stogdill, 1975; Yukl, 2010).

Theories proposed in the past decade emphasize leaders' symbolic behaviors, inspirational and visionary messages, 
non-verbal communication, appeal to ideological values, intellectual challenges to those being led, and expectations of self-sacrifice on the leaders' part at a level that reaches far beyond their concrete duties. Leaders endow work with meaning by connecting it to moral aims, commitment, and trying to influence factors in the environment of those being led (Levy, 2008; Yukl, 2010).

Leadership encompasses a set of qualities that includes setting goals, defining a vision, realizing that vision, and leading others towards achieving the desired goals. Successful leaders develop a vision based on personal and professional values that influence others. There is a research consensus that personal relationships are central to leadership (Bush \& Glover, 2003).

Heller (2002) argued that a person in a leadership position is expected to exhibit leadership characteristics, shape the organizational climate in a hierarchical manner, and interact with followers. Joint decision-making allows for involving multiple people in the process, enabling any individual member to influence how the group acts in response to their common goals. A model of effective leadership is created by a dynamic interaction between leaders, followers, and their circumstances (Popper, 2007). The leader directs the actions or attitudes of group members through various techniques of influence, ranging from coercion to persuasion.

Further, it has been found that followers prefer democratic, supportive, and participatory leadership with an accommodating style, rather than an authoritarian style (Oplatka, 2015). This highlights the importance of a participatory approach, in which the burden of leadership is divided among multiple people. Participatory leadership emphasizes the personal development of all members of the work team. This leadership style is characterized by mechanisms of joint decision-making that create engagement, dialogue, community, and an ongoing discussion about building shared values. Another characteristic of participatory leadership is a focus on identifying the special contributions of each group member (Chrislip \& Larson, 1994; Sergiovanni, 1984). Participatory leadership incorporates reciprocity between leader and followers and is based on interpersonal relationships. It is aimed at a specific purpose (Coleman \& Fitzgerald, 2008).

A recent study proposes that leaders in the academic sector should display "authentic leadership" in order to improve the overall performance of their team's projects. This can also contribute to the sustainable performance of universities (Tak et al., 2019). Dwivedi et al. (2020) propose that there should be autonomy in decision-making and a balance between change and stability: "Covid-19 reflected on agility and adaptive governance. Existing institutional structures and tools can enable adaptivity and agility, which can be complimentary approaches. Agility sometimes conflicts with adaptability, centralized and decentralized decision-making, for both innovation and bureaucracy, and both science and politics."

\section{Leadership during a Crisis or Emergency Situation}

The sheer unpredictability of the Covid-19 outbreak has made it challenging for leaders to respond to it. The pandemic is a "landscape scale" crisis: an unexpected event occurring at enormous and overwhelming speed, resulting in a high degree of uncertainty that gives rise to feelings of disorientation, loss of control, and emotional upheaval (Arnold et al., 2020; D’Auria \& De Smet, 2020).

Those in leadership positions at institutions of higher education throughout the world have responded to the crisis by closing campuses and moving all educational activities online in order to "flatten the curve" (Ahmed et al., 2018). However, leaders must move forward while avoiding rash or rushed decisions: "In a time of crisis, leaders must act swiftly and with foresight but also with careful consideration of options, consequences and side effects of actions taken" (Netolicky, 2020, p. 2). While leadership in a time of crisis is imperfect and sometimes makes mistakes, it is clear that there must be a flexible response to eliminate or reduce risk factors and mitigate the crisis.

Leadership is of particular importance during emergencies and crises. Seeger et al. (1998) define a crisis as a specific, unpredictable, and unconventional event or series of events that creates high levels of uncertainty and threatens the organization's ability to achieve its goals. Crises present opportunities to reveal leadership and to test the existing leadership. In a crisis situation, a system may lose its flexibility as a result of failing to deal with a threat or responding ineffectively at a critical turning point. In times of crisis, a threat becomes a reality; feared and undesirable events actually occur. The transition from a feared scenario to a real crisis exacerbates the psychological stress among individuals and the system as a whole, and various systems may cross their threshold of endurance. It may require extended time for systems to cope with this new situation, and the ability to function during the crisis may be diminished (Janis, 1989). In a crisis, there is a need for a leadership style that enables others to lead. Abolio (1999) defines the role of a leader during an emergency as being a leader of leaders. This means "deepening" the organizational leadership, delegating authority, and overseeing the use of human resources. Deepening the leadership refers to involvement in organizational activities, enabling their continuation, maintaining a positive mood, and offering tools for decision-making. During a crisis, it is crucial to support leadership traits that are expressed by others in the organization. This requires leaders who are self-confident, secure in their professional authority, who do not feel threatened by competition, are able to support the work of others, and are willing to delegate responsibility. This type of leader exhibits a decentralized style that offers 
employees ways to develop their own internal leadership. Deep leadership transforms the leader into an active partner with followers. This type of leader is not a charismatic visionary who is elevated high above the followers. Rather, this type of leader has the ability to empower followers, allows them freedom of thought and action, and enables them to be co-leaders. This leader is a "first among equals". Under certain conditions, a leader can even relinquish leadership and become a follower (Abolio, 1999). Similar approaches appear in Harris (2002), Leithwood (1994), and Leonard and Howitt (2007), who advocate for decentralized leadership as an alternative to traditional models of hierarchical leadership. Decentralization and deep leadership are recommended approaches to leadership at all times, but especially during emergencies. Leaders with experience in crisis management may use the emergency situation to leverage change and create a new reality that will benefit the followers (Tzur, 2004).

Previous research has focused on formal leadership, such as in politics and the military. This type of leader makes decisions, directs, explains, and mediates reality to the public in order to maintain functional continuity during an emergency. The expectation is that leaders will offer solutions and convey optimism and enthusiasm in order to influence those around them. During a crisis, leaders tend to display a range of emotions in their efforts to direct their followers. They must exercise discretion as to which emotions to express and which to withhold (George, 2000). It is important for leader to understand how to manage and regulate their emotions in times of crisis, or when dealing with any adverse events that occur in the course of their work (Humphrey 2005; Oplatka, 2018).

During an emergency, leadership must deal with the emotional and mental challenges surrounding uncertainty, and the need for quick responses to dramatic change. They must propose solutions as they deal with unanticipated and unfamiliar issues. People expect their leaders to minimize the impact of the crisis. Despite the extreme conditions of an emergency, leaders must maintain a sense of normalcy and make careful decisions, because their decisions involve risks and have consequences on the personal level, and in some cases, the national level as well (Rosenman et al., 2014).

During an emergency, leadership skills are critical to the survival of any organization, institution, or nation. Previous research has examined the functioning of leadership in crisis situations such as war or natural disasters (earthquakes, tsunamis), or the management of trauma centers in a clinical/medical arena. There is a lack of research on the issue of leadership during a global pandemic, but it is possible to learn from research on studies of emergencies in the medical field, and to make a connection with the issue under investigation in the current study. For example, effective communication and leadership are noted as essential in emergency responses, in order to improve health outcomes and increase patient safety. Effective leadership is associated with effective teamwork and more positive outcomes in emergency situations and with improved staff engagement (Manning, 2016; Rosenman et al., 2014).

Boin et al. (2005) examined how leaders face strategic challenges, risks, and political opportunities, as well as mistakes they make, traps they avoid, and various crisis management paths. They formulated five core tasks of leadership during a crisis: sense-making, decision-making, meaning-making, terminating, and learning. These processes relate to removing barriers to recognizing and understanding the crisis, knowing the organizational limitations, and assessing its psychological dimensions. Demonstrating leadership performance in times of crisis includes evaluating alternatives, making critical decisions, team building, and the execution of decisions (Boin et al., 2005).

Another factor in crisis management is related to achievement. It is necessary for leaders to perform their duties and to model the characteristics of leadership to their followers, so they can become partners in the process (Kadibesegil, 2008). Crises present leadership opportunities, allowing "ordinary" people to move to the forefront, make unexpected contributions, and even develop into leaders themselves. During a crisis, a leader is born as the need arises (Tutar, 2004).

A more critical approach asserts that the academic assessment regarding the importance of leadership in times of crises is impressionistic at best. It is well known that leaders can exacerbate a crisis by ignoring impending threats, making unwise decisions, or taking careless actions (Boin \& 't Hart, 2010). Leadership can be a double-edged sword. It can be valuable, extricating followers from the crisis, or it can be destructive and thoughtless, and even aggravate the crisis.

\section{Adaptive Leadership in Times of Crisis}

Adaptive leaders do more than make changes. They recognize potential changes and carefully consider which is the best path to positively impact the organization. Adaptive and agile leadership involves behavioral changes that are appropriate to situational changes (Mahsud et al., 2010). Adaptive leaders are aware of leader-follower relationships, and consider factors in the environment within which leaders and followers operate (Glover et al., 2002).

Adaptive leadership is less pertinent to routine times, because, by definition, it involves adaptation to an unusual situation that requires unconventional responses and tools that are not in usual toolbox. An adaptive leadership response spans the gap between the organization's aspirations, goals, and its operational capability. Adaptive leadership helps individuals and organizations adjust to and thrive in challenging environments. This approach is based on the research of Heifetz et al. (2009), which shaped the definitions and drew the outline for leadership training and development. 
Adaptive leadership during a crisis refers to the realization of leadership in the face of complex situations that require rapid change, and during which the current authority is insufficient. Adaptive leadership refers to a type of action and not a specific person. In adaptive leadership, actions are based on broad, systemic thinking. The leader drives processes that are undertaken by many people together. Adaptive leadership does not refer to a single, authoritative leader, but rather a system that responds to changes in its environment. This is presented as the preferred path of action, based on systemic understanding, and leading to systemic change (Heifetz et al., 2009, p. 14). Any person in any role can act to promote systemic change and take a position of adaptive leadership. This process involves risk for the person leading the change.

Tzur (2004) defined adaptive leadership as having central significance, especially in situations where multiple populations turn to a leader in the hope of receiving assistance, support, and protection against the factors causing a change or state of emergency. This theoretical approach is appropriate for the analysis of the various situations presented in the current article.

\section{Research Goals}

1. To analyze key processes undertaken by the leadership of Ohalo College following the outbreak of the Covid-19 pandemic to ensure the organization's continued functioning during this crisis.

2. To quantitatively examine the evaluation (degree of approval) of the lecturers regarding the steps taken by the college leadership.

3. To deduce practical insights and conclusions regarding adaptive leadership of an academic institution during a crisis.

\section{Methodology}

\section{Research Methods}

The present study employed a mixed-methods approach utilizing qualitative and quantitative measures. This design was chosen for various reasons. It sought to offer an answer to the research questions, enabling a multidimensional analysis and understanding of the key processes undertaken by the college's leadership. Mixed methods help to reduce biases (Tashakkori \& Teddlie, 2003) that might arise since the researchers were involved as members of the college leadership, participating in the processes described in the study.

The qualitative portion of the study is based on action research methodology, using a thematic analysis of documents in order to identify descriptive variables. This part of the analysis uses the "circle of action and reflection," a model based on Altrichter et al.'s work (2007). The model consists of four stages (data collection, interpretation, consequences and ideas for action, and action/reflection) that describe the action and reflection methodology, which relies on the laws of group dynamics. In the first stage, we collected relevant data in the form of documents, including meeting notes, protocols, and government guidelines that the college received. In the second stage, the data was analyzed using categorical analysis techniques. During the analysis, four key content categories were identified. In the third stage, we formed a timeline of the primary actions undertaken by the college's leadership. In the fourth stage, we adopted an action-reflection approach, based on McNiff's (2002) writings, in which action research is described as a platform for professional development that can help participants grow and examine their day-to-day work in a reflective manner.

As both researchers and participants in this study, utilizing a multidimensional, integrated research methodology was helpful to us; while we examined the findings, we were able to reflect on the question of whether our work as college leaders aligns with our expectations for ourselves and our work processes. Finally, on the basis of this analysis, and in accordance with the research questions, we synthesized the process related to adaptive/agile college leadership during the Covid-19 pandemic. The findings were discussed and interpreted, seeking to understand their meanings and implications (Shakedi, 2011). The holistic and layered qualitative analysis helped us create a model of the processes of agile leadership and decision-making during the Covid-19 pandemic (see Figures 1-3).

To support our qualitative findings and examine them from a different angle, namely, the university lecturers' point of view, we used quantitative measures. The quantitative portion consisted of an attitude questionnaire constructed especially for the current study. The questionnaire underwent face validation and was examined by three experts holding doctorates in education. It was distributed via Google Drive to all of the college's lecturers $(\mathrm{N}=130)$. Thus, participants were recruited through convenience sampling, which is thought to offer robust knowledge. The goal of the questionnaire was to gain insight into the perspectives of the lecturers and see how they evaluated the actions undertaken by the college leadership. Several steps were taken in order to establish the reliability of the data and the quantitative findings. In the first stage, both authors of this article separately performed the value measurements, using statistical tests (ANOVA, Pearson). In the second stage, the questionnaire responses were examined by both researchers, who then compared their results. In order to increase the reliability of the questionnaire, a large number of statements (17) was constructed, as detailed below. 
Each category included a number of questionnaire statements so that the categorical expected values would be as accurate as possible. We determined the internal consistency reliability for each category: a high correlation was found between the categorical expected values and the questionnaire items (Cronbach's alpha $(\alpha)=0.819$ ).

Furthermore, we tested the reliability of the first three indices: maintaining direct contact with the management $(8$ statements); managing the training and practicum processes (4 statements); and persistence in distance teaching and contact with students ( 2 statements). Cronbach's alpha $(\alpha)$ measures were found to be high, with a high degree of stability and consistency in the statements for each of the indices.

\section{Research Process}

The study describes the decisions and steps undertaken between March and July 2020 by the leadership of Ohalo College, following the announcement of various closures due to Covid-19. As noted above, qualitative data was collected from documents, and quantitative data was collected via a questionnaire. The questionnaire, created especially for this study, underwent face validation, and was examined by three experts holding doctorates in education. It was distributed via Google Drive to the entire population of lecturers at the college $(\mathrm{N}=130)$. The distribution was done as a single-stage procedure among a convenience sample. Responses were anonymous. Statistical analysis was conducted on the findings, as presented in the tables. It quantitatively examines the degree to which the college lecturers approved of the leadership's performance.

The authors of the article were involved in leading the processes described, and therefore their personal and professional experiences are also considered.

The theoretical framework is based on approaches in previous research on leadership. During a crisis, leaders are forced to function in a rapidly changing situation. This requires dynamic approaches, decision-making processes, goal-setting behaviors, and efforts to maintain relationships among the organization's members. The theoretical approach in the current case study is based on key concepts such as adaptive leadership and deep leadership.

The main research hypothesis predicts that a positive relationship will be found between the decisions made by the college leadership and the degree of satisfaction expressed by the college lecturers regarding the leadership's performance.

\section{Study Population}

The study population included 48 subjects. Of these, 38 were lecturers in the field of education (79.2\%), 5 were lecturers in the school of physical education (10.4\%), and 5 were lecturers in a variety of other disciplines (10.4\%). Ten of the lecturers have seniority of less than 5 years (20.9\%), 19 lecturers have 5-9 years of seniority (39.6\%), and 19 lecturers have seniority of 10 years or more $(39.6 \%)$.

\section{Research Tools}

A questionnaire was specifically constructed to address the research questions and goals. The questionnaire included 17 statements, each requiring a response along a five-point Likert scale, in which a high value represented a high degree of agreement with the statement. These statements were associated with seven topical categories: maintaining direct contact with the leadership (statements 1, 3, 4, 8, 9, 10, 15, 16); management of training processes and experience (statements 5, 7,13 ); persistence in maintaining contact with students during distance learning (statements 6 , 14); degree of personal difficulty (statement 11); lecturers' desire to be involved in leadership decisions (statement 2); perspective regarding the consistency over time of the changes enacted (statement 12); and frequency of use of overall resources (statement 17). The mean of each participant's responses to the statements in these seven categories was calculated, and thus the seven indices of the study were verified.

The questionnaire was reviewed for validity by three content experts holding doctorates in education.

\section{Qualitative Findings: The Lesson is the Process.}

\section{From Theory to Reality: How did the Ohalo College Leadership Respond to the Covid-19 Pandemic?}

In this section, we will present the main qualitative findings. Four content areas were identified:

1. Implementation of government guidelines. 2. Preservation and maintenance of training processes. 3. Continuation of students' practical experience (practicum). 4. Maintenance of direct contact between students, lecturers, and administrative staff.

At the onset of this crisis, the college leadership convened a meeting to define its main goals, which guided the various processes undertaken by the college throughout this period (see Fig. 1).

Implementation of state guidelines. Following the varied and graduated guidelines on the general closure, the college was forced to reduce the number of workers, adhere to social distancing, limit the number of people present (no more than $30 \%$ of the administrative staff), and adhere to rules of hygiene termed the "purple badge". In light of the closure 
and the strict guidelines on social distancing, the college made a general transition to learning and teaching via online platforms. This presented challenges to the faculty and the students alike. The college complied with guidelines, despite confusing and frequently modified instructions. It became immediately clear that it could not be assumed or expected that each individual would read all of the incoming information. Therefore, all stakeholders had to fully share information at all times.

Preservation and maintenance of training processes. The motto adopted by the leadership was "continue as usual, in an unusual mode". Following the announcement of the closure, an "agile" transition took place. Within 48 hours, 700 courses, 1500 students, and 140 lecturers were transitioned to ERT mode. They used various platforms, primarily Zoom, which was new and unfamiliar to most of them prior to this time.

Continuation of the practical experience (practicum). A central element of teacher training is the practicum. It was decided to continue the practicum through distance teaching and learning sessions. The college students taught school pupils via Zoom. When it became possible to return to schools and kindergartens, they continued to teach and gain experience in the typical mode. The unit for the practicum was prepared according to three different scenarios, in order to cover all possibilities during the Covid-19 pandemic (remote learning, in-person training at the institution, or a hybrid experience). All stakeholders involved in the training were partners in the transition processes (students, teacher-trainer, school teacher, kindergarten teacher, etc.). Frequent meetings were held, all information was shared transparently, and decisions were made collaboratively.

Maintenance of direct contact between students, lecturers, and administrative staff. A second motto was adopted: "We (the college administrators) are here for you at all times". Continuous dynamic interaction was maintained among all stakeholders, including administrative staff, academic staff, and students. A routine was created for maintaining contact during this time through emails, personal phone calls from department heads and lecturers to students, enlisting the student association, and involving students in the process. Zoom conversations were initiated between staff members, students, and the administrative support services. Emotional and psychological counseling services were offered via Zoom. Conversations were held via Facetime with heads of activity groups. Social activities were held via Zoom.

\section{Adaptive leadership at the implementing organization}

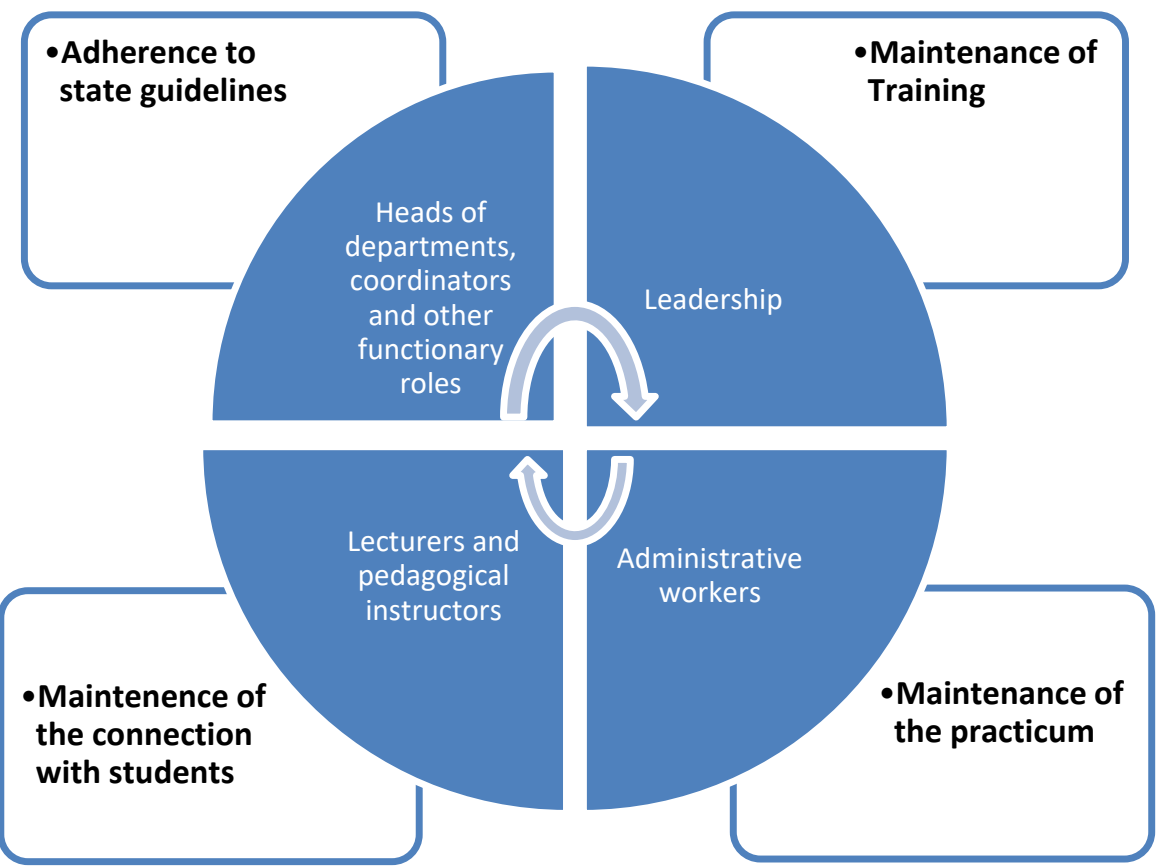

Figure 1. Defining the Main Goals and Partners Goal Implementation

Below is a description of the timeline that details primary actions undertaken by the college leadership.

Stage 1: The surprise followed by the agile response.

March 12 through April 20, 2020 was a lockdown period. A rapid transition was made to remote methods for learning, 
teaching, and administrative tasks. This was a time of great uncertainty and involved a period of adaptation to this new situation.

March 12, 2020. Following receipt of state guidelines regarding the expected closure, the college leadership held an emergency assessment meeting. The goal was to create and prepare an emergency Innovation and Technical Support Unit for ERT (similar to a "war room" in situations of security threats or military conflict). On the afternoon of March 12 , letters were sent to all faculty and students on behalf of the head of the college regarding the guidelines, with an explanation that within 48 hours of receiving the notice of the closure, the college was moving towards ERT.

March 15, 2020. Distance learning began. All courses and activities were transferred to remote modes.

March 16, 2020. The Internal Academic Council prepared the department heads. All department heads reported on their level of readiness for the change. The head of the college updated everyone with information and steps to be taken. Joint decisions were made through discussion and consultations.

\section{Stage 2: Functioning in the "Corona Routine" - May 20 through the end of the semester on June 26, 2020. In this stage a number of steps were taken:}

The assessment processes for online tests in a variety of examination methods (multi-text, multiple-choice, oral, and more) were reinforced and accelerated. The test moderators and the staff were assessed by the academic director and the technological infrastructure was prepared by creating the Innovation and Technical Support Unit.

Some students were invited for a number of supplementary practical and didactic lessons, in accordance with the "purple badge" guidelines (state guidelines for maintaining social distance, hygiene, seating arrangements, wearing face masks, class placement according to number of participants per square meter, etc.).

Evaluations of the Innovation and Technical Support Unit: A special portal was opened using the Moodel system, an online synchronous support and training system that provides tools for lecturers with videos, explanations, etc.

Following the initial "surprise" phase at the beginning of the second semester, we saw various initiatives and a burst of renewed creativity on the part of staff, lecturers, and other personnel, such as creating greeting videos, songs, enrichment activities, technological guidance for department heads, and more.

All the lecturers prepared weekly reports for the department heads, using WhatsApp groups set up for this purpose. Daily activities included meetings via Zoom, written reports, and supervision via Moodel.

Lecturers collaborated on a variety of platforms, enabling them to share their accumulated knowledge and experiences regarding what was successful and what was less so.

The contract with the company operating the Unicko virtual classroom platform was terminated. It was replaced by synchronous instruction conducted via Zoom.

The Mofet Institute, a national intercollegiate center for the research and development of curricula and programs in teacher education, offered a wide range of courses, facilitation and training sessions, and participatory activities to the lecturers and pedagogical instructors.

A set of support services were offered to students, including calls by phone, Zoom, or Facetime with the head of the college, department heads, lecturers, and other faculty members. Other services addressed inquiries and offered (online) psychological counseling and emotional support.

The remote experience and online environment replaced classroom learning. Pedagogic instructors prepared students for distance learning. For the practicum unit, the college students, together with a school teacher and/or kindergarten teacher, prepared and guided a wide variety of educational tasks and assignments for pupils in schools and kindergartens, all of which were conducted via Zoom.

The outcomes of a variety of practicum experiences were collected and documented. Processes were analyzed and a new model for conducting the practicum and training sessions using ERT was created by Ohalo College. This model was distributed by the Ministry of Education to many other colleges.

Weekly meetings of the leadership team were held via Zoom, and contact was maintained with the students and faculty. For example, a videotaped Passover holiday greeting was prepared and distributed to all students, as well as a Zoom gathering for students and their families to "raise a glass in toasting the holiday".

After the Passover holiday break, supervision of the academic processes became the responsibility of the head of the Faculty of Education and the head of the School of Physical Education. There was close supervision of department heads and coordinators of the academic specializations.

Faculty and department heads thought through how to conduct assessments, tests, and work online, and managed relevant 
changes.

Zoom licensing was purchased and the internet bandwidth for the college was expanded. The college consulted with the Mofet Institute regarding services to be used at this unusual time, and assessed the model for conducting lessons.

Regular updates were distributed to the members of the academic and administrative teams through announcements and letters regarding what is expected for the following two weeks.

Monthly Zoom meetings were held with the head of the college, the faculty and department heads, and all the lecturers.

At the lecturer level: Assistance and personal support was provided for lecturers who were not proficient in conducting remote teaching. The Innovation and Technical Support Unit's "war room" provided support, updates, and knowledge via weekly Zoom sessions. Information was disseminated regarding meetings, lectures, and various training sessions offered by the Mofet Institute and others.

At the student level: Every two weeks, the heads of the college, departments, and faculties sent letters to the students. For the first two weeks, the college initiated personal phone calls with all students. Various staff members were assigned certain groups of students to call.

The administrative team opened a dedicated file for student inquiries on various topics, and handled all questions.

Feedback was disseminated from surveys on distance learning during the ongoing processes, with relevance to the various courses, teaching methods, and assessment processes.

One of the basic premises that guided the college leadership in decision-making was distributing relevant information to all employees in real time. The organization strove to avoid being misled by inaccurate information, which often emerged from daily news media, and to avoid overwhelming people with unnecessary details or unverified scenarios. They tried to offer as much certainty and stability as possible in this unsettling time of crisis, and to offer a sense of belonging, trustworthiness, and connection.

In summary, the central and meaningful motto that guided the processes of leadership and management during this crisis was "flatten the hierarchy curve" and provide a scope for action, with an emphasis on enabling people's leadership potential. Such a process optimizes leadership in a crisis, by dividing responsibilities and enabling others to assume leadership. Each coordinator and department head took full responsibility and demonstrated leadership. They showed their understanding of the scope of the situation by looking a few steps ahead, preparing and evaluating each teaching scenario (frontal or online). There was a flow of information among the partners.

From all the aspects described above, we can develop a theoretical model that synthesizes existing models and the processes that took place at Ohalo College during the Covid-19 pandemic (see Figure 2).

$$
\text { Pandemic }
$$

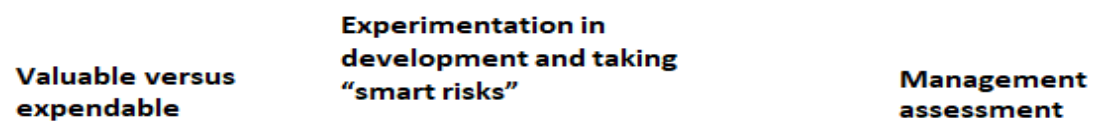
expendable development and taking
"smart risks"

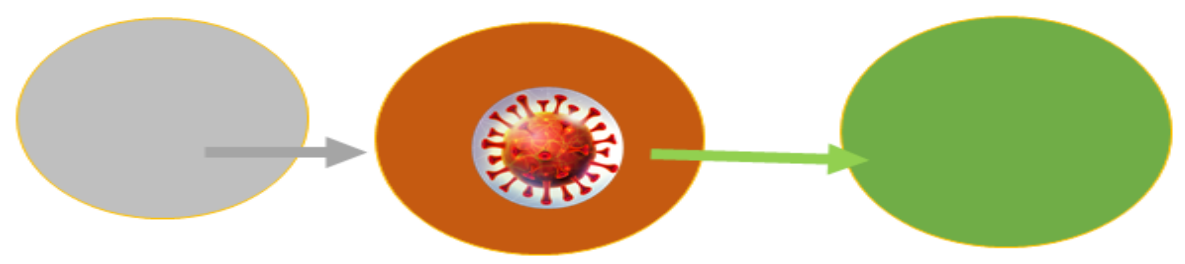

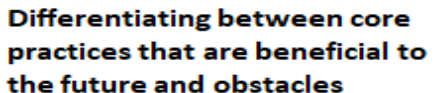

the future and obstacles

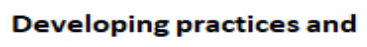

testing next steps

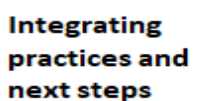

next steps

Figure 2. Processes of "Agile Leadership" and Decision Making During the Covid-19

Valuable versus expendable: Identify which of the goals and practices are the most important, significant, central to the 
organization, and crucial for the future; identify those that pose obstacles in a changing era of emergencies and uncertainty.

Experimentation with "smart risks": Develop and test practices for the future.

Management assessment: Integrating next steps and practices to identify what may be adopted in the future. The path to be taken was clarified, and the college prepared for a variety of potential scenarios. Performance was evaluated via the survey on distance teaching, which was distributed to students (this subject was presented in a previous study, Nissim \& Simon, 2020) and the leadership activity evaluation survey, which was distributed to lecturers.

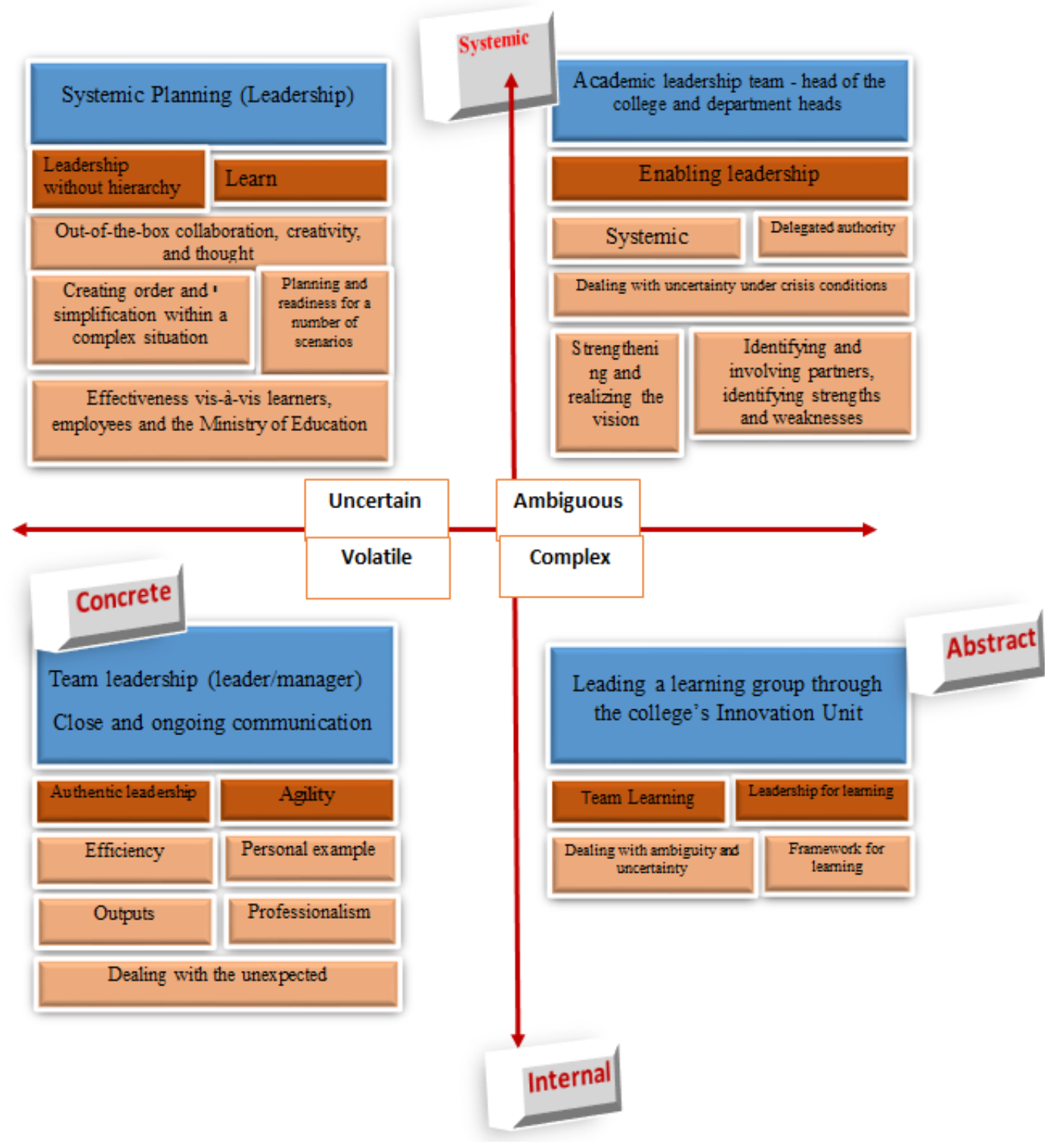

Figure 3. College Leadership in the Environment Created by the Covid-19 Pandemic

\section{Quantitative Findings}

Having described the theoretical infrastructure and the processes undertaken, we now examine and analyze the conduct of the college leadership from the perspective of the lecturers, who were partners throughout the process.

Following the first phase of shock and uncertainty, by mid-semester (about a month following the closure) the college had entered a "Corona Routine". At this time, we assessed the performance of the leadership and how the lecturers evaluated the decisions the leadership made. Key findings are listed in Table 1. 
Table 1. General Traits of college's leadership

The Research Indices $(\mathrm{N}=48)$

\begin{tabular}{|l|c|c|c|c|c|}
\hline Index & $\begin{array}{l}\text { Number of } \\
\text { Statements }\end{array}$ & Range & Mean & $\begin{array}{c}\text { Standard } \\
\text { Deviation }\end{array}$ & $\boldsymbol{\alpha}$ \\
\hline $\begin{array}{l}\text { Maintaining direct contact with } \\
\text { management }\end{array}$ & 8 & $2.38-5.00$ & 4.02 & .71 & .861 \\
\hline $\begin{array}{l}\text { Management of training and } \\
\text { experience processes }\end{array}$ & 4 & $3.50-5.00$ & 4.43 & .50 & .710 \\
\hline $\begin{array}{l}\text { Persistence in distance learning } \\
\text { and contact with students }\end{array}$ & 2 & $2.50-5.00$ & 4.61 & .53 & .648 \\
\hline Degree of personal difficulty & 1 & $1.00-5.00$ & 2.35 & 1.04 & -- \\
\hline Lecturers' desire to be involved & 1 & $1.00-5.00$ & 3.27 & 1.36 & -- \\
\hline $\begin{array}{l}\text { Position regarding the } \\
\text { preservation of changes over } \\
\text { time }\end{array}$ & 1 & $1.00-5.00$ & 3.26 & 1.11 & - \\
\hline $\begin{array}{l}\text { Frequency of use of overall } \\
\text { resources }\end{array}$ & 1 & $1.00-5.00$ & 3.68 & .98 & - \\
\hline
\end{tabular}

The reliability of the first three indices, as measured by Cronbach's alpha $(\alpha)$, was found to be high. This attests to a high degree of stability and consistency in the statements within each of the categories. Table 2 presents the mean of the respondents' answers to each of the 17 statements.

Table 2. Mean and Standard Deviation of the Survey questions and statments $(\mathrm{N}=48)$

\begin{tabular}{|l|r|r|}
\hline & Mean & \multicolumn{1}{|l|}{$\begin{array}{l}\text { Standard } \\
\text { Deviation }\end{array}$} \\
\hline $\begin{array}{l}\text { To what extent did you feel updated with relevant information regarding the } \\
\text { changes? }\end{array}$ & 4.27 & .74 \\
\hline Would you like to feel more involved? & 3.27 & 1.36 \\
\hline $\begin{array}{l}\text { To what extent did you feel that the college leadership was attentive to your } \\
\text { needs? }\end{array}$ & 4.09 & .95 \\
\hline To what extent did you feel comfortable contacting people in official roles? & 4.23 & .90 \\
\hline To what extent were you aware of the ongoing training processes? & 4.33 & .78 \\
\hline How persistent were you in the distance learning processes? & 4.73 & .57 \\
\hline $\begin{array}{l}\text { To what extent do you think the college leadership was able to maintain } \\
\text { teaching processes? }\end{array}$ & 4.48 & .62 \\
\hline $\begin{array}{l}\text { To what extent do you think a sense of "togetherness" was maintained, } \\
\text { despite the social distancing regulations? }\end{array}$ & 3.83 & .95 \\
\hline $\begin{array}{l}\text { To what extent did you receive support from the college (department heads, } \\
\text { support center, leadership)? }\end{array}$ & 4.19 & 1.00 \\
\hline To what extent did you receive support from your colleagues? & 4.15 & 1.17 \\
\hline $\begin{array}{l}\text { How much personal difficulty did you experience while dealing with this } \\
\text { uncertain situation? }\end{array}$ & 2.35 & 1.04 \\
\hline $\begin{array}{l}\text { To what extent do you think the changes enacted during the "Corona period" } \\
\text { will be preserved over time? }\end{array}$ & 3.26 & 1.11 \\
\hline $\begin{array}{l}\text { Rate the conduct of the college leadership in directing the various processes } \\
\text { during the second semester. }\end{array}$ & 4.17 & .75 \\
\hline Rate your conduct with the students. & 4.50 & .65 \\
\hline Rate the degree to which the conduct of the college was proactive. & 4.11 & .79 \\
\hline How often were the college's overall resources utilized? & 3.29 & 3.68 \\
\hline $\begin{array}{l}\text { How often was there personal dialogue among lecturers, colleagues, and } \\
\text { college officials? }\end{array}$ & & .98 \\
\hline
\end{tabular}

The findings indicate that the respondents saw themselves as being highly persistent in the distance teaching processes (average 4.73). They rated their conduct with the students positively (4.50). In their opinion, the college leadership 
preserved the teaching processes in a positive way (4.48), and the respondents highly rated their degree of awareness regarding the existence of ongoing training processes (4.33). They said they felt comfortable contacting those in official roles (4.23). An interesting finding is that the subjects did not indicate experiencing a high degree of personal difficulty while dealing with the uncertainty during the time of the Covid-19 crisis (only 2.35).

\section{Correlations between Research Indices}

Pearson tests were performed to examine the correlations between the research indices, as shown in Table 3.

Table 3. Pearson Correlations Between Research Indices $(\mathrm{N}=48)$

\begin{tabular}{|l|r|r|r|r|r|r|}
\hline Index & 1 & 2 & 3 & 4 & 5 & 6 \\
\hline $\begin{array}{l}\text { 1. Maintenance of direct contact with } \\
\text { leadership }\end{array}$ & -- & & & & & \\
\hline $\begin{array}{l}\text { 2. Management of training and } \\
\text { experience processes }\end{array}$ & $.747^{* *}$ & -- & & & & \\
\hline $\begin{array}{l}\text { 3. Persistence in distance learning and } \\
\text { contact with students }\end{array}$ & .035 & $.293^{*}$ & -- & & & \\
\hline 4. Degree of personal difficulty & -.244 & -.173 & -.114 & -- & & \\
\hline 5. Lecturers' desire to be involved & -.230 & -.071 & .059 & $.335^{*}$ & -- & \\
\hline $\begin{array}{l}\text { 6. Perception of the preservation of } \\
\text { changes over time }\end{array}$ & $.443^{* *}$ & $.411^{* *}$ & .095 & .031 & .192 & -- \\
\hline 7. Frequency of use of overall resources & $.469^{* *}$ & $.431^{* *}$ & .094 & -.118 & .073 & $.296^{*}$ \\
\hline
\end{tabular}

$* \mathrm{p}<0.05 * * \mathrm{p}<0.01$

It can be seen that there are moderately positive correlations between the maintenance of direct contact with the college leadership, managing training and practicum processes, perceived preservation of changes over time, and the frequency of use of overall resources. There are stronger positive correlations of medium intensity between the management of the training and practicum processes, persistence in distance teaching, contact with students, perceived preservation of changes over time, and the frequency of use of overall resources. In addition, moderately positive correlations were found between the degree of personal difficulty and the desire of the lecturers for involvement, as well as between the perceived preservation of changes over time and the frequency of use of overall resources.

\section{Summary, Discussion and Conclusions}

In this case study, we demonstrate how the leadership of an academic institution for teacher and educator training operated in a deep and adaptive manner. They created a dynamic interaction with all stakeholders. It was necessary to prepare and implement a rapid, agile, and flexible solution under conditions of uncertainty, and was essential to continue organizational activities as they transitioned from active learning on the college campus to a comprehensive set of distance learning, with teaching and other activities conducted remotely and in accordance with state guidelines.

As the organization dealt with forced closure in the face of the Covid-19 pandemic, the main goal underlying the college's activities was changed and they adopted a number of sub-goals suitable to an "agile" organization. The speed with which this transition took place was unprecedented. The practices described above can be linked to the theory of adaptive leadership, as presented by Heifetz et al. (2009). They reflect decisions that move in both directions along the axis between adaptive leadership and organized implementation, and between high levels of abstract ideas and low levels of concrete activities, that is, formulation of a strategy and its implementation in a wide range of tactics (as illustrated in Figure 2). During the crisis, issues that were at the core of the organization received the most attention from all stakeholders, including leadership, lecturers, and students. Multiple meetings and conversations were held with all stakeholders, in order to give them an opportunity to express their point of view. The role of the leadership was to respond to the newly arisen situation, and to evolve organizationally as the situation developed. This approach is consistent with Abolio's (1999) assertion that supporting the leadership skills among others is critical in times of crisis. Decentralized leadership creates learning situations that can develop internal leadership. Deep leadership makes the leader an active partner with followers. Such a leader is perceived as being able to empower followers, grant them intellectual and executive independence, and indeed become leaders themselves (Abolio, 1999).

At the outset of the study, we hypothesized that a positive relationship would be found between the decisions made by the college leadership and the satisfaction of the lecturers, in terms of whether the provided training and leadership's conduct were beneficial to the students and faculty. This hypothesis was confirmed by the findings, as presented above.

The study set out to answer the research question: What was the perspective of the lecturers regarding the steps taken by the leadership? To answer this question, a questionnaire was sent to the lecturers and the responses were analyzed. The 
results show there was a high level of satisfaction on the part of the lecturers regarding the conduct of the college administration during the Covid-19 pandemic. This is true, despite the fact that the lecturers were presented with varied and changing requirements, which greatly deviated from their normal pre-pandemic routine. They had to teach using ERT, access a wide range of tutorials, attend Zoom meetings, and in general adapt to a new and surprising situation that required a significant investment of time, beyond what would have been considered acceptable previously.

The lecturers (study participants), according to their responses to the survey, were persistent in the remote teaching process. In their opinion, their conduct with the students was positive. They said they perceived the college leadership as maintaining teaching processes in a highly positive way. They said there was awareness of the ongoing training processes and that they felt comfortable contacting those in official roles.

A second research question was: What are the main insights that can be learned from this test case in order to create models of valuable, adaptive, and agile leadership under conditions of crisis and uncertainty? The main goal of the college's activities was transformed into targeted, specific sub-goals to address the Covid-19 pandemic: to be an "agile" organization and to move all administrative, teaching, and other educational activities from a physical, frontal format to an online form, especially using the Zoom platform.

These processes occurred quickly and with agility, in order to continue the training processes, enable teaching and learning anywhere and anytime, and to maintain the health of students and faculty in accordance with guidelines and orders issued by the state. The speed with which this transition took place was unprecedented. For these processes to occur effectively, it was necessary to apply skills and capabilities of adaptive leadership and agility in the face of the crisis, to adopt channels of direct communication, to allow other people to take initiative and participate in leadership, and especially to flatten the hierarchy curve. This created a situation in which there was no longer one leader with others acting as followers; rather, each member of the faculty, department heads, and other officials could become leaders during the emergency. They took responsibility for various areas, initiated action, were creative, and acted in accordance with all the relevant factors. This approach is consistent with that described by Abolio (1999) as a leader who is the "first among equals".

Leadership in an institution of higher education requires special traits. This can be seen as being in alignment with theoretical approaches that include: shaping and imparting a vision, encouraging learning and collaboration, building meaning, imparting knowledge, providing opportunities for creativity, disseminating viewpoints and values, enabling ongoing dialogue, and maintaining and managing reflective processes in a collaborative and current climate (Schneider $\&$ Monsonego, 2010). We believe that in times of crisis, these traits need to be even more strongly expressed, so that the leader is operating in accordance with the framework and is suited to the situation.

\section{Study Limitations}

This research is a case study in which the researchers were also involved as the leaders of the processes described. Therefore, the subjectivity of the researchers in light of their professional roles impacted the choice of research methodology. The research is pioneering in the field, and is not based on an extensive base of previous research literature that deals directly with the situation under investigation, namely leadership of an academic institution during the Covid-19 pandemic.

The study population in the quantitative survey is a representative, if small, sample. Therefore, the limited database is nevertheless valid.

\section{References}

Abolio, B. (1999). Hatvach hamaleh shel hamanhegut: B'derech liha-alat ramat ha-effectiviut shel hayachid, hakevutzah, vehairgun [The full range of leadership: The way to improve the level of effectiveness of the individual, the group, and the organization]. In A. Gonen \& A. Zakai (Eds.), Manhigut vipituach manhigut: Mihalacha lima'aseh. [Leadership and leadership development: From theory to practice] (pp. 65-92). Lior Publishers of the Ministry of Defense.

Ahmed, F., Zviedrite, N., \& Uzicanin, A. (2018). Effectiveness of workplace social distancing measures in reducing influenza transmission: a systematic review. BMC Public Health, 18(518). https://doi.org/10.1186/s12889-018-5446-1

Altrichter, H., Posch, P., \& Somekh, B. (2007). Teachers investigate their work: An introduction to action research across the professions (2nd ed.). Routledge.

Amirault, R. J., \& Visser, Y. L. (2009). The university in periods of technological change: A historically grounded perspective. Journal of Computing in Higher Education, 21(1), 62-79.

Axinn, W. G., \& Pearce, L. D. (2006). Mixed method data collection strategies. Cambridge University Press. 
Bass, B. M. (1960). Leadership, psychology, and organizational behavior. Harper.

Boin, A., \& 't Hart, P. (2010). Organising for effective emergency management: Lessons from research. Australian Journal of Public Administration, 28(4), 357-371.

Boin, A., 't Hart, P., Stern, E., \& Sundelius, B. (2005). The politics of crisis management: Public leadership under pressure. Cambridge University Press.

Bush, T., \& Glover, D. (2003). School leadership: Concepts and evidence. National College for School Leadership.

Chrislip, D., \& Larson, C. (1994). Collaborative leadership: How citizens and civic leaders can make a difference. Jossey-Bass Publishers.

Clark, V. L. P., \& Creswell, J. W. (2008). The mixed methods reader. Sage Publications.

Coleman, M., \& Fitzgerald, T. (2008). Gender and leadership development. In J. Lumby, G. Crow, \& P. Pashiardis (Eds.), International handbook on the preparation and development of school leaders (pp. 119-136). Routledge.

Cuban, L. (1988). The managerial imperative and the practice of leadership in schools. State University of New York Press.

D'Auria, G., \& De Smet, A. (2020). Leadership in a crisis: Responding to the coronavirus outbreak and future challenges. McKinsey and Company. https://www.mckinsey.com/ /media/McKinsey/Business\%20Functions/Organization/Our\%20Insights/Leadership $\% 20$ in $\% 20 \mathrm{a} \% 20$ crisis $\% 20$ Responding $\% 20$ to $\% 20$ the $\% 20$ coronavirus $\% 20$ outbreak $\% 20$ and $\% 20$ future $\% 20$ challenge s/Leadership-in-a-crisis-Responding-to-the-coronavirus-outbreak-and-future-challenges-v3.pdf

Dwivedi, Y. K., Hughes, D. L., Coombs, C., Constantiou, I., Duan, Y., Edwards, J. S., ... Raman, R. (2020). Impact of COVID-19 pandemic on information management research and practice: Transforming education, work and life. International Journal of Information Management, 55, 102211. https://doi.org/10.1016/j.ijinfomgt.2020.102211

Fernandez, A. A., \& Shaw, G. P. (2020). Academic leadership in a time of crisis: The Coronavirus and COVID19. Journal of Leadership Studies, 14(1), 39-45. https://doi.org/10.1002/jls.21684

Forsyth, D. R. (1990). Group dynamics. Cole Publishing.

George, J. M. (2000). Emotions and leadership: The role of emotional intelligence. Human relations, 53(8), 1027-1055.

Glover, J., Rainwater, K., Jones, G., \& Friedman, H. (2002). Adaptive leadership: Four principles for being adaptive (Part 2). Organization Development Journal, 20(2), 18-38.

Goodarzi, B., Shakeri, K., Ghaniyoun, A., \& Heidari, M. (2018). Assessment correlation of the organizational agility of human resources with the performance staff of Tehran Emergency Center. Journal of Education and Health Promotion, 7, 142.

Harris, A. (2002). Distributed leadership in schools: Leading or misleading?. Paper presented at the British Educational Leadership, Management and Administration Society Annual Conference, Birmingham.

Heifetz, R. A. (1994). Leadership without easy answers. Belknap Press of Harvard University Press.

Heifetz, R., Grashow, A., \& Linsky, M. (2009). Leadership in a (permanent) crisis. Harvard Business Review, 87(7-8), 62-69, 153. PMID: 19630256.

Heifetz, R., Grashow, A., \& Linksy, M. (2009). The practice of adaptive leadership. Harvard Business Press.

Heller, D. A. (2002). The power of gentleness. Educational Leadership, 59(8), 76-79.

Humphrey, R. H. (2005). Empathy, emotional expressiveness, and leadership. Proceedings of the Southern Management Association.

Janis, I. L. (1989). Crucial decisions: Leadership in policymaking and crisis management. Free Press.

Kadibesegil, S. (2008). Crisis announces it is coming. Mediacat Publishing.

Leithwood, K. (1994). Leadership for school restructuring. Educational Administration Quarterly, 30(4), 498-518.

Levy, A. (2008). Nihul vimanhigut shinui vichadshanut [Management and leadership: Change and innovation]. Rimon Publishing.

Leonard, H. B., \& Howitt, A. M., (2007). Against desperate peril: High performance in emergency preparation and response. In D. E. Gibbons (Ed.), Communicable crises: Prevention, response, and recovery in the global arena (1st ed., pp. 20-25). Information Age Publishing.

McNiff, J. (2002). Action Research: Principles and Practice. Routledge 
Mahsud, R., Yukl, G., \& Prussia, G. (2010). Leader empathy, ethical leadership, and relations-oriented behaviors as antecedents of leader-member exchange quality. Journal of Managerial Psychology, 25(6), 561-577. https://doi.org/10.1108/02683941011056932

Manning, J. (2016). The influence of nurse manager leadership style on staff nurse work engagement. Journal of Nursing Administration, 46, 438-443.

Morien, R. (2018). Pedagogical agility, and agile methodologies in computer system development education. International Journal of Advanced Intelligence Paradigms, 11(1-2), 9-32.

Netolicky, D. M. (2020). School leadership during a pandemic: Navigating tensions. Journal of Professional Capital and Community.

Nissim, Y., \& Simon, E. (2019). The teacher-leader's image: Between personal characteristics and strategies empowering learners. Journal of Education and Learning, 8, 136-146.

Nissim, Y. (2020). Draw me a shepherd: Student-teachers' perceptions and metaphors on the image of the "leader-teacher". Higher Education Studies, 10(2), 1-24.

Oplatka, Y. (2015), Yesodot minhal hachinuch: Manhigut vinihul bi'irgun hachunuchi [Fundamentals of educational leadership: Management and leadership in an educational organization]. Pardes Publishing Ltd.

Oplatka, Y. (2018). Regishut behora'ah u'binuhul beit sefer: Asefut maamarim [Emotions in teaching and school management: A collection of articles.] Mofet Institute.

Overby, E., Bharadwaj, A., \& Sambamurthy, V. (2006). Enterprise agility and the enabling role of information technology. European Journal of Information Systems, 15(2), 120-131.

Popper, M. (2007). Manhigut meatzevet: mabat psichologi [Transformational leadership: A psychological perspective]. University of Tel Aviv, pp. 75-102.

Richardson, L., \& St. Pierre, E. A. (2005). Writing: A method of inquiry. In N. K. Denzin \& Y. S. Lincoln (Eds.), Handbook of qualitative research (3rd ed., pp. 959-978). Sage Publications.

Rosenman E., Shandro, J., Ilgen, J., Harper, A. L., \& Fernandez, R. (2014). Leadership training in health care action teams: A systematic review. Academic Medicine, 89(9), 1295-1306. https://doi.org/10.1097/ACM.0000 000000000413

Schneider, A., \& Monsonego, I. (2010). Oryanut rigshit: Tvunah vetovanah beyachasei enosh: Nidvach mahuti betifisat hanihul habeit sifrit [Emotional literacy: Wisdom and insight in human relations, an essential layer in understanding school management.] Beit Berel.

Seeger, M. W., Sellnow, T. L., \& Ulmer, R. R. (1998). Communication, organization and crisis. In M. E. Roloff (Ed.), Communication yearbook. Sage Publications.

Sergiovanni, T. (1984). Leadership and excellence in schooling. Educational Leadership, 41(5), 4-13.

Shkedi, A. (2011). Ha-mashmaut me-achoraey hamilim: Metodologiyot bemechkar eichutanit, halacha lemaaseh [The meaning behind the words: methodologies in qualitative research in practice]. Tel Aviv: Ramot. (Hebrew).

Stogdill, R. (1975). The evolution of leadership theory. Academy of Management Proceedings, pp. 4-6. https://doi.org/10.5465/ambpp.1975.4975786

Strom, D. L., Sears, K. L., \& Kelly, K. M. (2014). Work engagement: The roles of organizational justice and leadership style in predicting engagement among employees. Journal of Leadership \& Organizational Studies, 21, 71-82.

Tak, J., Seo, J., \& Roh, T. (2019). The influence of authentic leadership on authentic followership, positive psychological capital, and project performance: Testing for the mediation effects. Sustainability, 11(21), 6028.

Taşç1, G., \& Titrek, O. (2020). Evaluation of lifelong learning centers in higher education: A sustainable leadership perspective. Sustainability, 12, 22.

Tashakkori, A., \& Teddlie, C. (2003). Issues and dilemmas in teaching research methods courses in social and behavioural sciences: US perspective. International Journal of Social Research Methodology, 6(1), 61-77.

Tutar, H. (2004). Crisis and stress management. Seckin Publishing.

Tzur, N. (2004). Rhetorica politit: Manhigim Yisraelim bimatzavim lachatz [Political rhetoric: Israeli leaders under pressure]. Kibbutz Hamiyuchad.

Yukl, G. (2010). Leadership in organizations. Pearson. 


\section{Copyrights}

Copyright for this article is retained by the author(s), with first publication rights granted to the journal.

This is an open-access article distributed under the terms and conditions of the Creative Commons Attribution license (http://creativecommons.org/licenses/by/4.0/). 